\title{
SEMI-MARKOV MODEL OF REPLACEMENT SYSTEM WITH MINIMAL REPAIR
}

\author{
A. Neubauer ${ }^{*}$, L. Knopik ${ }^{* *}$, M. Szubartowski ${ }^{* * *}$, K. Migawa $^{\dagger}$
}

\begin{abstract}
This paper analyzes the application of the semi-Markov process to the construction of a 4-state system of preventive replacements with minimal repair. Asymptotic availability was adopted as a function. An example shows that with certain assumptions the availability assumes an exactly one maximum.
\end{abstract}

Keywords: semi-Markov process, availability, minimal repair, perfect repair, preventive replacement

\section{Introduction}

Most operation systems suffer from failure due to the age of technical objects and their long lifetime. In order to reduce the number of failures of technical objects, strategies for preventive replacements have been introduced into management systems. Several different replacement strategies have been developed to reduce system maintenance costs. Among the many methods of the evaluation and the control of repair systems, the semi-Markov processes have been implemented (Chen et al., 2005, Grabski, 2014 and Knopik et al., 2017). Management of operation systems requires various activities related to maintaining reliability and availability of technical objects. These activities are divided into two types: preventive (PM) and repair (CM). Typically, repairs require prior damage diagnosis and identification. Therefore, the costs and repair times are generally higher than the costs and times of preventive measures. For some operation systems, it is also possible to repair a damaged technical object via minimal repair (MR). The minimal repair restores the damaged technical object (element) to the state before the failure occurred, without changing its failure rate. Based on this argument, many practical models of exchanges with minimal repair have been suggested in literature. The concept of a minimal (imperfect, inaccurate) repair was introduced in paper (Brown, 1983). The minimal repair model assumes that when the failure occurs, perfect repair is carried out with probability p and minimal repair is carried out with probability $1-\mathrm{p}$. Perfect repair restores the technical object to "good-as-new" condition, while minimal repair to "bad-asold" condition. If $\mathrm{p}=0$, repair is always minimal, whereas if $\mathrm{p}=1$, repair is always perfect. In paper (Block et al., 1985), an assumption was made that the probability of perfect repair depends on the age of the technical object at the time of failure. On the other hand, a generalization of the model presented in paper (Brown, 1983) into a two-dimensional version was proposed in paper (Sheu et al., 1992). This paper analyzes the possibility of using semi-Markov processes to build a model of preventive replacements in systems with minimal repair. Its availability is examined as criteria function.

RNDr. Andrzej Neubauer, DSc.: Nicolaus Copernicus University, Gagarina Street 11, 87-100 Toruń, Poland, aneub@umk.pl

** Assoc. Prof. Leszek Knopik, PhD.: Faculty of Management, UTP University of Science and Technology, Fordońska Street 430, 85-790 Bydgoszcz, Poland, knopikl@utp.edu.pl

*** RNDr. Mirosław Szubartowski, DSc.: Management Business and Service, Fordońska Street 40, 85-719 Bydgoszcz, Poland, analityk@karor.com.pl

† Assoc. Prof. Klaudiusz Migawa, PhD.: Faculty of Mechanical Engineering, UTP University of Science and Technology, Al. prof. S. Kaliskiego 7, 85-789 Bydgoszcz, Poland, klaudiusz.migawa@utp.edu.pl 


\section{A model of replacement system with minimal repair}

This paper examines the semi-Markov model of preventive age-dependent replacements. The 4-state semi-Markov $X(t)$ process is presented with state space $S=\{1,2,3,4\}$. If $X(t)=i$, then the presented process at moment $t$ is in state $i$. It is assumed that state 1 is correct operation state, state 2 is minimal repair state, state 3 is perfect repair state, state 4 is the preventive replacement state. Through $z_{i}, i=1,2$, 3 , 4, the profit per time unit for state $i$ is determined. It is assumed that $\tau_{0}<\tau_{1}<\tau_{2}<\ldots<\tau_{\mathrm{k}}<\ldots$ are leap moments and $\mathrm{v}_{\mathrm{k}}=\tau_{\mathrm{k}}-\tau_{\mathrm{k}-1}$ for $\mathrm{k} \geq 1, \mathrm{v}_{0}=0$ are times of remaining at process states $\mathrm{X}(\mathrm{t})$. The semi-Markov process is fully defined if the initial distribution is known:

$$
P\{X(0)=i\}=P_{i}(0) ; i=1,2, \ldots, 4
$$

and its semi-Markov kernel is defined by matrix:

$$
\mathrm{Q}(\mathrm{t})=\left[\mathrm{Q}_{\mathrm{ij}}(\mathrm{t})\right] \text {, where } \mathrm{Q}_{\mathrm{ij}}(\mathrm{t})=\mathrm{P}\left\{\mathrm{X}\left(\tau_{\mathrm{k}+1}\right)=\mathrm{j}, \tau_{\mathrm{k}+1}-\tau_{\mathrm{k}}<\mathrm{t} \mid \mathrm{X}\left(\tau_{\mathrm{k}}\right)=\mathrm{i}\right\} ; \mathrm{i}, \mathrm{j}=1,2, \ldots, 4
$$

A sequence of random variables $\mathrm{X}\left(\tau_{\mathrm{k}}\right), \mathrm{k} \in \mathrm{N}$ is a Markov chain embedded in the semi-Markov process with probability transfer matrix:

$$
P=\left[P_{i j}\right]=\left[Q_{i j}(\infty)\right] ; \quad i, j=1,2, \ldots, 4
$$

Random variables $T_{i}, i=1,2, \ldots, 4$ stands for times of remaining at states of process $X(t)$ and have distribution functions in the form of:

$$
\mathrm{F}_{\mathrm{i}}(\mathrm{t})=\mathrm{P}\left\{\mathrm{T}_{\mathrm{i}}<\mathrm{t}\right\}=\mathrm{P}\left\{\tau_{\mathrm{k}+1}-\tau_{\mathrm{k}}<\mathrm{t} \mid \mathrm{X}\left(\tau_{\mathrm{k}}\right)=\mathrm{j}\right\}
$$

or, alternatively:

$$
F_{i}(t)=\sum_{j=1}^{4} Q_{i j}(t) ; i=1,2, \ldots, 4
$$

Distribution function for time of remaining at state $\mathrm{i}$, before transfer to state $\mathrm{j}$, is defined as follows:

$$
F_{i j}(t)=P\left\{\tau_{k+1}-\tau_{k}<t \mid X\left(\tau_{k+1}\right)=j, \quad X\left(\tau_{k}\right)=i\right\} ; i, j=1,2, \ldots, 4, k \in N
$$

For distribution function $F_{1 j}(x)$ defined by formula (2), it is assumed that $F_{1 j}(x)=F_{1}(x)$ for $j=2,3,4$. When building criteria function, the limit theorem for finite semi-Markov processes is used (Howard, 1971 and Grabski, 2002 and Knopik, 2010). It is assumed that the mean values $\mathrm{ET}_{\mathrm{i}}, \mathrm{i}=1,2, \ldots, 4$ are finite, positive and the Markov chain $\mathrm{X}\left(\tau_{\mathrm{k}}\right), \mathrm{k}=0,1,2, \ldots$, has one ergodic class. These assumptions lead to the formulation of the limit theorem in the form:

$$
P_{j}=\lim _{t \rightarrow \infty} P\{X(t)=j\}=\lim _{t \rightarrow \infty} P\{X(t)=j \mid X(0)=i\} ; i, j=1,2, \ldots, 4
$$

where:

$$
P_{j}=\frac{p_{j}^{*} E T_{j}}{\sum_{i=1}^{4} p_{i}^{*} E T_{i}}
$$

where $\mathrm{p}_{\mathrm{j}}^{*}, \mathrm{j}=1,2, \ldots, 4$ is a limit distribution of Markov chain $\mathrm{X}\left(\tau_{\mathrm{k}}\right), \mathrm{k} \in \mathrm{N}$ embedded in semi-Markov process. Limit probabilities $\mathrm{p}_{\mathrm{j}}{ }^{*}$ are the solution of the system of linear equations:

$$
\sum_{\mathrm{i}=1}^{4} \mathrm{p}_{\mathrm{i}}^{*} \mathrm{p}_{\mathrm{ij}}=\mathrm{p}_{\mathrm{j}}^{*} \text { with the condition that } \sum_{\mathrm{i}=1}^{4} \mathrm{p}_{\mathrm{i}}^{*}=1 ; \mathrm{j}=1,2,3,4
$$

On the basis of papers (Knopik, 2010 and Knopik et al., 2018), the function is expressed by the formula: 


$$
g(x)=\frac{\sum_{i=1}^{4} \mathrm{z}_{\mathrm{i}} \mathrm{p}_{\mathrm{i}}^{*} \mathrm{ET}_{\mathrm{i}}}{\sum_{\mathrm{i}=1}^{4} \mathrm{p}_{\mathrm{i}}^{*} \mathrm{ET}_{\mathrm{i}}}
$$

It is assumed that probability transition matrix of an embedded Markov chain has the following form:

$$
\mathrm{P}=\left[\begin{array}{cccc}
0 & \mathrm{P}_{12} & \mathrm{P}_{13} & \mathrm{P}_{14} \\
\mathrm{P}_{21} & 0 & \mathrm{P}_{23} & 0 \\
1 & 0 & 0 & 0 \\
1 & 0 & 0 & 0
\end{array}\right]
$$

Limit probabilities for Markov chain embedded in semi-Markov process $\mathrm{X}(\mathrm{t})$ are as follows:

$$
\mathrm{p}_{1}^{*}=\frac{1}{\mathrm{M}} ; \quad \mathrm{p}_{2}^{*}=\frac{\mathrm{p}_{12}}{\mathrm{M}} ; \quad \mathrm{p}_{3}^{*}=\frac{\left(\mathrm{p}_{13}+\mathrm{p}_{12} \mathrm{p}_{23}\right)}{\mathrm{M}} ; \quad \mathrm{p}_{4}^{*}=\frac{\mathrm{p}_{14}}{\mathrm{M}}
$$

where $\mathrm{M}=2+\mathrm{p}_{12} \mathrm{p}_{23}$.

It is assumed that after time $\mathrm{x}$ expires, if the object has not been damaged, it moves to the preventive replacement state 4 . A new process is obtained with a new probability transition matrix $\mathrm{P}(\mathrm{x})$ embedded in Markov chain. In relation to the matrix $\mathrm{P}$ described above, only the first row of the matrix changes. Specifically:

$$
p_{12}(x)=p_{12} F_{12}(x) ; \quad p_{13}(x)=p_{13} F_{13}(x) ; \quad p_{14}(x)=p_{14}(x) F_{14}(x)+R_{1}(x)
$$

On the basis of (Knopik, 2010), function takes the following form: $g(x)=\frac{L(x)}{M(x)}$, where:

$$
\begin{gathered}
\mathrm{L}(\mathrm{x})=\mathrm{z}_{1} \mathrm{ET}_{1}(\mathrm{x}) \mathrm{p}_{1}{ }^{*}(\mathrm{x})+\mathrm{z}_{2} \mathrm{ET}_{2} \mathrm{P}_{2}{ }^{*}(\mathrm{x})+\mathrm{z}_{3} \mathrm{ET}_{3} \mathrm{P}_{3}{ }^{*}(\mathrm{x})+\mathrm{z}_{4} \mathrm{ET}_{4} \mathrm{p}_{4}{ }^{*}(\mathrm{x}) \\
\mathrm{M}(\mathrm{x})=\mathrm{ET}_{1}(\mathrm{x}) \mathrm{p}_{1}{ }^{*}(\mathrm{x})+\mathrm{ET}_{2} \mathrm{p}_{2}{ }^{*}(\mathrm{x})+\mathrm{ET}_{3} \mathrm{p}_{3}{ }^{*}(\mathrm{x})+\mathrm{ET}_{4} \mathrm{p}_{4}{ }^{*}(\mathrm{x})
\end{gathered}
$$

where $\operatorname{ET}_{1}(\mathrm{x})=\int_{0}^{\mathrm{x}} \mathrm{R}_{1}(\mathrm{t}) \mathrm{dt}$.

On the other hand, $\mathrm{ET}_{2}, \mathrm{ET}_{3}, \mathrm{ET}_{4}$ are mean values of the object remaining at states 2, 3, and 4 . For availability $\mathrm{g}(\mathrm{x})$ it is assumed that $\mathrm{z}_{1}=1, \mathrm{z}_{2}=\mathrm{z}_{3}=\mathrm{z}_{4}=0$. Taking the above assumptions and solutions into consideration (5), the availability $\mathrm{g}(\mathrm{x})$ on the basis of papers (Grabski, 2002, and Knopik, 2010, and Knopik et al., 2018) takes the following form:

$$
g(x)=\frac{E T_{1}(x)}{E_{1}(x)+F_{1}(x) B+C}
$$

where:

$$
\mathrm{B}=\mathrm{ET}_{2} \mathrm{p}_{12}+\mathrm{ET}_{3}\left(\mathrm{p}_{12} \mathrm{p}_{23}+\mathrm{p}_{13}\right)-\mathrm{ET}_{4}\left(\mathrm{p}_{12}+\mathrm{p}_{13}\right) ; \quad \mathrm{C}=\mathrm{ET}_{4}
$$

\section{Numerical example}

This section analyzes the example of determining the value of the function $g(x)$, in the case when $g(x)$ is the availability. The following data were used for the calculation: values of non-zero matrix elements P: $\mathrm{p}_{12}=0.2, \mathrm{p}_{13}=0.6, \mathrm{p}_{14}=0.2, \mathrm{p}_{21}=0.2, \mathrm{p}_{23}=0.7$; expected values of remaining at process states $\mathrm{X}(\mathrm{t})$ : $\mathrm{ET}_{2}=0.2, \mathrm{ET}_{3}=0.5, \mathrm{ET}_{4}=0.1$ and for the correct operation of $\mathrm{T}_{1}$ the Weibull distribution was adopted with the scale parameter $b=6$. The calculations were made for three values of Weibull distribution form parameter $\mathrm{c}, \mathrm{c} \in\{4,5,9\}$ corresponding to mean values of correct operation time $\mathrm{ET}_{1}: 5.44,5.61,5.68$. 
Figure 1 shows the obtained function $\mathrm{g}(\mathrm{x})$ results. In each of the analyzed cases there exists a value of optimal replacement time $\mathrm{x}$. In particular, the criteria function reaches a maximum: $\mathrm{g}_{\max }(\mathrm{x})=0.959$ for $\mathrm{c}=4$ and $\mathrm{x}=3$; $\mathrm{g}_{\max }(\mathrm{x})=0.969$ for $\mathrm{c}=5$ and $\mathrm{x}=3.6$; $\mathrm{g}_{\max }(\mathrm{x})=0.973$ for $\mathrm{c}=9$ and $\mathrm{x}=4$.

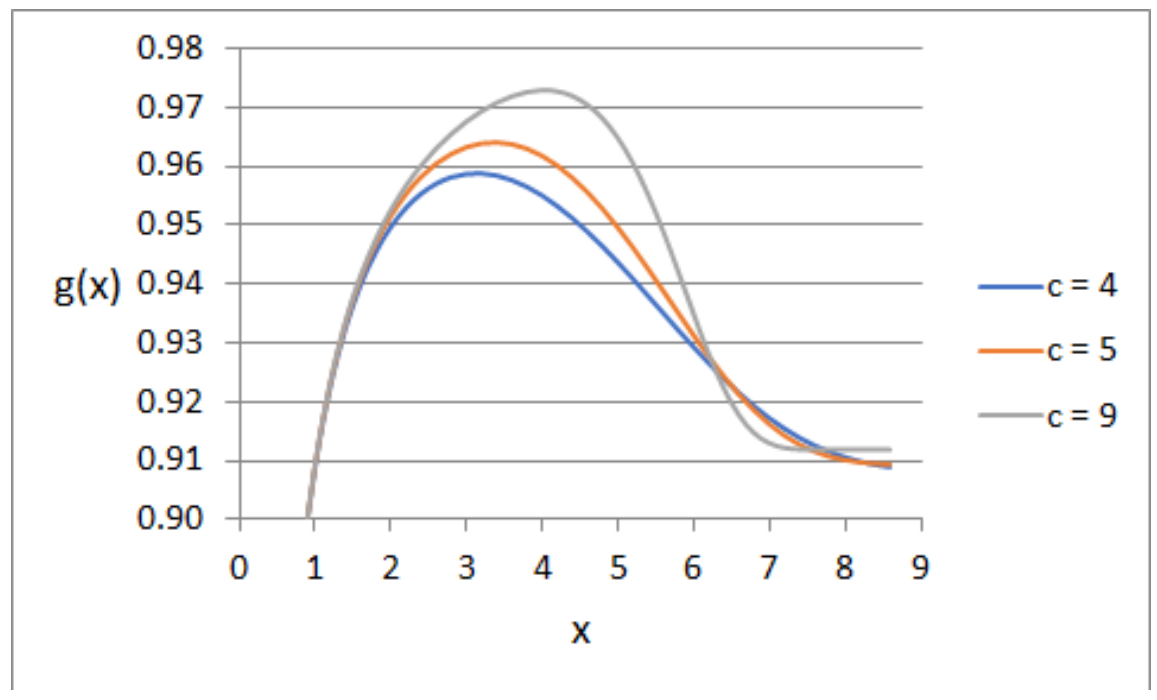

Fig.1: Charts of value changes of availability $g(x)$ depending on preventive replacement time $x$, for $c \in\{4,5,9\}$

\section{Conclusions}

Implementation of semi-Markov processes in optimization of availability brings about the possibility to effectively determining the maximum value of said rate. This paper showed this through an example in which time to failure has Weibull distribution. To examine whether the criterial function reaches its maximum also for other types of time-to-failure distributions, it is advisable to formulate conditions sufficient for the existence of the maximum criterial function.

\section{References}

Block, H.W., Borges, W.S. and Savits, T.H. (1985) Age-dependent minimal repair. Journal Applied Probability, 22, pp. 370-385.

Brown, M. (1983) Imperfect repair. Journal Applied Probability, 20, pp. 851-859.

Chen, D-Y. and Trivedi, KS. (2005) Optimization for condition-based maintenance with semi-Markov decision process. Reliability Engineering and System Safety, Elsevier, 90, pp. 25-29.

Grabski, F. (2002) Semi-Markov models of reliability. IBS PAN. Warsaw.

Grabski, F. (2014) Semi-Markov processes: Applications in system reliability and maintenance. Elsevier, Amsterdam.

Howard, O. (1971) Dynamic probabilistic system. Vol. 2. Semi-Markov and decision processes. John Wiley.

Knopik, L. (2010) Method of choice efficiency strategy of the maintenance of technical object. University of Science and Technology in Bydgoszcz, Publishing Department, Dissertations no. 145.

Knopik, L. and Migawa, K. (2017) Optimal age-replacement policy for non-repairable technical objects with warranty. Eksploatacja i Niezawodnosc - Maintenance and Reliability, vol. 19, no. 2, pp. 172-178.

Knopik, L. and Migawa, K. (2018) Multi-state model of maintenance policy. Eksploatacja i Niezawodnosc Maintenance and Reliability, vol. 20, no. 1, pp. 125-130.

Sheu, S. and Griffith, W.S. (1992) Multivariate imperfect repair. Journal Applied Probability, 29, pp. 947-957. 